ISSN 0258-7122

Bangladesh J. Agril. Res. 37(3): 543-546, September 2012 Short Communication

\title{
MORPHOMETRICS OF CUCURBIT LONGICORN (Apomecyna saltator F.) COLEOPTERA: CERAMBYCIDAE REARED ON CUCURBIT VINES
}

\begin{abstract}
M. M. H. KHAN ${ }^{1}$
Keywords: Morphometrics, cucurbit longicorn, cucurbit.

The morphometrics of cucurbit longicorn, Apomecyna saltator F. were studied on ridge gourd (Luffa acutangula L.) in the laboratory. Results revealed that the mean length of larva and pupa was $13.90 \mathrm{~mm}$ and $11.74 \mathrm{~mm}$, respectively. Antennae were very long with mean length of $6.95 \mathrm{~mm}$. The length of pro, meso, and metathoracic legs was almost equal. The mean length of fore and hind wings were 8.21 and $10.56 \mathrm{~mm}$, respectively. Among the three stages of the pest, the highest mean weight was recorded in pupa.
\end{abstract}

The cucurbit longicorn, Apomecyna saltator Fabricius is widely distributed species in the Afrotropical, Oriental, Australasian regions (May, 1946; Duffy, 1980), Hawaii, and India (Samalo \& Parida, 1983; Samalo, 1985). This beetle was first reported in the state of Oahu in 1896 and has been reported in Hawaii, Kauai, and Maui. This is a pest of various Cucurbitaceae and infrequent pests of cucumbers, pumpkins, squashes, watermelons, and gourds. The grubs of this beetle tunnel in the vines and stems of many cucurbit plants. Grubs bore into the main vines of plants and produce a swelling of the stem. The feeding tunnel is usually directed towards nodes and is filled with glutinous waste material (May, 1946). The larvae enter the stem and infest plants usually showing no conspicuous symptoms. Under very severe infestations, young plants may die, but older plants often live to produce reduced yields. The biology of this beetle has not been studied well and the duration of each life stage is not known. May (1946) reports that the cucurbit longicorn may have two or three generations per year in melons in Queensland, Australia which is slightly warmer than Hawaii. Many behavioural adaptations of the females are known involving the preparation of sites of oviposition.

The morphometrics of cucurbit longicorn, Apomecyna saltator, were studied by rearing on ridge gourd (Luffa acutangula L.) in the laboratory of the Department of Entomology, BSMRAU, Gazipur during May to July 2007. The infested vines of three cucurbit plants having immature stages of A. saltator were collected from the field. Ninety pieces of about $10 \mathrm{~cm}$ sized cut vines were collected from the field of infested sweet gourd, cucumber, and ridge gourd. Ten vine pieces out of 30 pieces of each of the cucurbits were used for the collection of larva, pupa, and adult, respectively, and these stages were preserved in alcohol

${ }^{1}$ Department of Entomology, Patuakhali Science and Technology University (PSTU), Dumki, Patuakhali, Bangladesh. 
solution for measurements. Data on the morphometric measurements of different life stages viz., full grown larva, pupa, adult, and appendages viz., antennae, legs and wings were made using a stereomicroscope (Plates A-D).

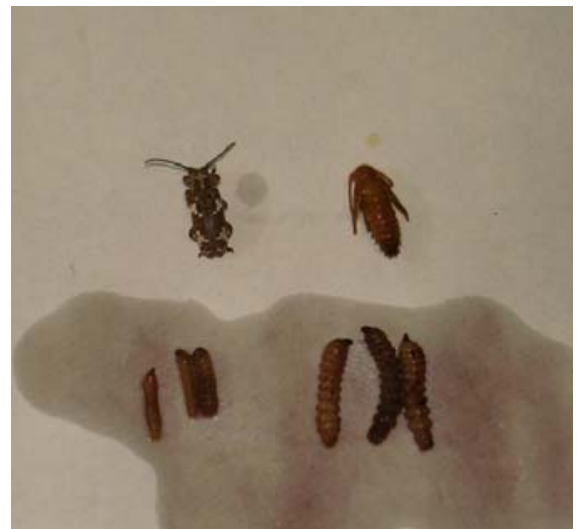

A. Immature and adult stages of $A$. saltator

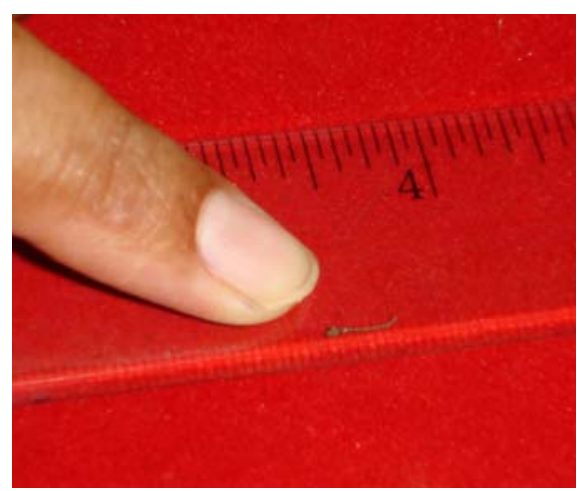

C. Measurement of antenna

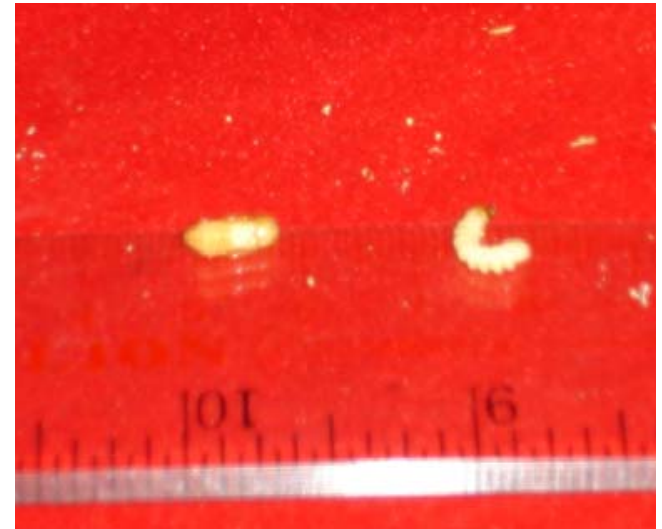

B. Measurement of larva and pupa of $A$. saltator

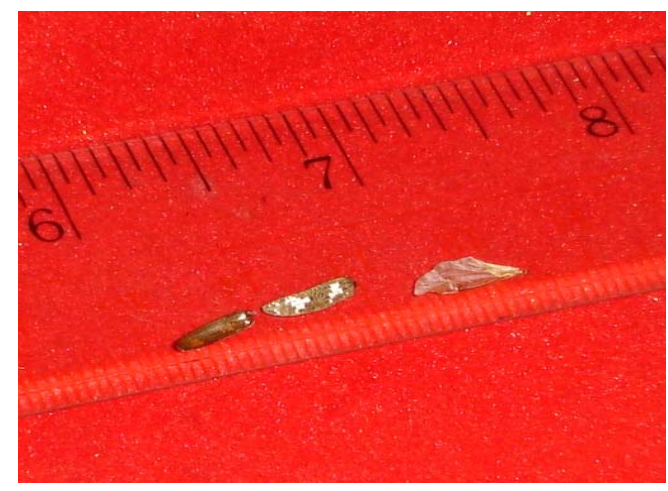

D. Measurement of wings

The weight of full grown larva, pupa, and adult was measured by using an electronic balance. Means and standard errors (SE) were calculated from ten observations. The full grown larva of cucurbit longicorn, Apomecyna saltator, was cream coloured. The mean length was $13.90 \mathrm{~mm}$, and breadth across thorax and abdomen are 2.69 and $2.66 \mathrm{~mm}$, respectively (Table 1). This larva pupated within a fibrous cocoon constructing within the stem. The mean length of pupa was $11.74 \mathrm{~mm}$, and breadth across thorax and abdomen were 3.28 and $2.71 \mathrm{~mm}$, respectively (Table 1 ). The adult $A$. saltator was slate-gray beetle with several white spots arranged in three evenly $\mathrm{V}$ shaped markings across the wing. The adult measured $10.75 \mathrm{~mm}$ in length and 3.45 and $3.04 \mathrm{~mm}$ in breadth across thorax and abdomen, respectively with long antennae measuring $6.95 \mathrm{~mm}$ about two-thirds the length of the body (Table 1). The size of pro, meso, and 
metathoracic legs was almost the same being 5.14- $5.37 \mathrm{~mm}$ long. The hind wings were broader by about $2 \mathrm{~mm}$ than the fore wings (Table 1). Duffy (1980) reported that the cucurbit longicorn has very long antennae, about two-thirds the length of the body, usually 11-segmented and simple with scutellum rounded, elytra about two and a half times as long as broad and legs rather short and stout. The findings of the present study agreed with of Shah and Vora (1974) and May (1946) in melons in Queensland, Australia.

Table 1. Morphometrics of cucurbit longicorn, Apomecyna saltator.

\begin{tabular}{|c|c|c|}
\hline Life stages and appendages & Range (mm) & Mean \pm SE $(\mathrm{mm})$ \\
\hline \multicolumn{3}{|l|}{ Full grown larva } \\
\hline Length & $13.00-15.00$ & $13.90 \pm 0.21$ \\
\hline \multicolumn{3}{|l|}{ Breadth } \\
\hline -Across thorax & $2.40-3.00$ & $2.69 \pm 0.07$ \\
\hline -Across abdomen & $2.50-2.90$ & $2.66 \pm 0.05$ \\
\hline Weight (mg) & $30.90-93.50$ & $56.66 \pm 5.65$ \\
\hline \multicolumn{3}{|l|}{ Pupa } \\
\hline Length & $11.00-13.00$ & $11.74 \pm 0.24$ \\
\hline \multicolumn{3}{|l|}{ Breadth } \\
\hline -Across thorax & $3.00-3.50$ & $3.28 \pm 0.06$ \\
\hline -Across abdomen & 2.50-3.00 & $2.71 \pm 0.07$ \\
\hline Weight (mg) & 45.10-101.90 & $74.27 \pm 5.11$ \\
\hline \multicolumn{3}{|l|}{ Adult } \\
\hline \multicolumn{3}{|l|}{ Body } \\
\hline Length & $10.40-11.00$ & $10.75 \pm 0.08$ \\
\hline \multicolumn{3}{|l|}{ Breadth } \\
\hline -Across thorax & $3.20-3.80$ & $3.45 \pm 0.05$ \\
\hline -Across abdomen & $2.80-3.30$ & $3.04 \pm 0.05$ \\
\hline Weight (mg) & $12.50-67.70$ & $35.98 \pm 5.52$ \\
\hline \multicolumn{3}{|l|}{ Antennae } \\
\hline Length & $6.50-7.00$ & $6.95 \pm 0.05$ \\
\hline \multicolumn{3}{|l|}{ Leg length } \\
\hline Prothoracic & $5.00-5.40$ & $5.14 \pm 0.04$ \\
\hline Mesothoracic & $5.00-6.00$ & $5.31 \pm 0.10$ \\
\hline Metathoracic & $5.50-7.20$ & $6.37 \pm 0.17$ \\
\hline \multicolumn{3}{|l|}{ Wing length } \\
\hline Fore & $8.00-8.50$ & $8.21 \pm 0.06$ \\
\hline Hind & $10.00-11.00$ & $10.56 \pm 0.14$ \\
\hline
\end{tabular}


The pupa was heavier than larva and adult. Full grown larval weighed 30.9 to $93.5 \mathrm{mg}$. Pupal weighed 45.1 to $101.9 \mathrm{mg}$ and the adult was lighter in weight and ranging from 12.5 to $67.7 \mathrm{mg}$ (Table 1 ).

\section{References}

Duffy, E.A.J. 1980. A monograph of the immature stages of African timber beetles (Cerambycidae) Supplement. Commonwealth Agricultural Bureaux, Farnham, Royal.

May, A. W. S. 1946. Pests of Cucurbit Crops. Queensland Agricultural J. 62 (3): 137-150.

Samalo, A. P. and Parida, P. B. 1983. Influence of Spacing and Levels of Nitrogen on VineBorer Incidence and Yield of Pointed-Gourd. Indian J. Agric. Sci. 53 (7): 574-577.

Samalo, A. P. 1985. Chemical Control of Pointed Gourd Vine Borer, (Apomecyna saltator) Fabr. Madras Agric. J. 72 (6): 325-329.

Shah, A. H. and Vora, V. J. 1974. Biology of the Pointed Gourd Vine Borer, Apomecyna neglecta Pasc. (Cerambycidae: Coleoptera) in South Gujarat. Indian J. Ent. 36 (4): 308-311. 